\title{
Outcomes of Introducing a Mobile Interactive Learning Resource: Medical Students' Commentary on Prolonged Use
}

\author{
Chloe Challen $^{1}$ (D) $\cdot$ Peng Yao $^{1} \cdot$ Aayushi Bhargava $^{1} \cdot$ Charlotte Caves $^{1}$ \\ Published online: 19 December 2019 \\ (C) International Association of Medical Science Educators 2019
}

Dear editor,

We read with great interest the work of Friedmann et al. [1] about the first time use of an iBook to teach pre-clinical respiratory medicine. The article suggests that this is the first report of an interactive learning resource that entirely encompasses the content of a major organ system. Imperial College London has used interactive iBooks as course guides for all pre-clinical exams since 2015. As medical students who sat our first year exams at Imperial in 2015/2016, we have experienced this use of technology throughout our studies and would like to comment on our experience of prolonged iBook use.

Friedmann et al. highlight how the use of iBooks may enhance student engagement. Yet the article states that the benefit of iBooks appears limited as exam performance did not improve significantly. We would like to highlight that looking at these two factors alone may not reveal the true positive impact of iBook use. Li and Tsai [2] highlight how interactive resources can heighten student motivation and satisfaction. While student grades remained unchanged, their enjoyment and willingness to study may have improved, as suggested by the positive feedback obtained. Furthermore, Dowell and Small [3] found that increased learning strategies improved grades, contradicting this study's findings. Perhaps this difference is due to iBooks only being made for the Cardiology-Pulmonary-Renal block, as opposed to covering the entire curriculum.

At Imperial, all learning resources are integrated online and this continuity makes iBooks greatly useful in supplementing lecture slides. However, at Imperial, lecture slides are the core learning resource for pre-clinical students, unlike the students in this article with only 30-35\% reporting to study using PowerPoint slides. The benefits may therefore be dependent

Chloe Challen

cmc215@ic.ac.uk

1 Department of Medicine, Imperial College London, London, UK on the nature of the course. This is especially apparent as in our respiratory iBook, the notes for each lecture were written by the lecturer presenting that topic, as opposed to the two faculty members and three medical students in this study. This meant that at Imperial the iBooks were supplementary to lectures, alongside providing interactive tutorial questions. Furthermore, having lecturers write content for their own lectures potentially reduces the time required to produce iBooks compared to content written by medical students, as expert authors have a higher degree of knowledge. While Friedmann et al. have found limited benefits from interactive learning resources, the benefits of iBooks seem greater with increasing use of technology within pre-clinical medical education.

\section{Compliance with Ethical Standards}

Ethical Approval This is not applicable.

Informed Consent This is not applicable.

Conflict of Interest The authors declare that they have no conflict of interest.

\section{References}

1. Friedmann T, Bai JDK, Ahmad S, Barbieri RM, Iqbal S, Richman PS. Outcomes of introducing a mobile interactive learning resource in a large medical school course. Med Sci Educ. 2019:1-5. https:// doi.org/10.1007/s40670-019-00829-8.

2. Li LY, Tsai CC. Accessing online learning material: quantitative behavior patterns and their effects on motivation and learning performance. Comput Educ. 2017:286-97. https://doi.org/10.1016/j. compedu.2017.07.007.

3. Dowell DJ, Small FA. What is the impact of online resource materials on student self-learning strategies? J Mark Educ. 2011:140-8. https://doi.org/10.1177/2F0273475311410846.

Publisher's Note Springer Nature remains neutral with regard to jurisdictional claims in published maps and institutional affiliations. 